\title{
Inter-Bank Call Rate Volatility and the Global Financial Crisis:
}

\section{The Nigerian Case}

\author{
OLOWE, RUFUS AYODEJI \\ Department of Finance, University of Lagos, Lagos, Nigeria \\ Tel: 23-480-2229-3985 E-mail: raolowe@yahoo.co.uk
}

\begin{abstract}
This paper investigated the volatility of interbank call rates in Nigeria using GARCH $(1,1)$, EGARCH $(1,1)$, TS-GARCH $(1,1)$ and PARCH $(1,1)$ models in the light of the stock market crash and global financial crisis. Using data over the period, June 11, 2007 and May 20, 2009, volatility persistence and asymmetric properties are investigated for the Nigerian interbank call money market. The result shows that volatility is persistent. The hypothesis of asymmetry and leverage effect is rejected. It is found that the Nigerian interbank call money market returns show high persistence in the volatility but it shows clustering properties. The result shows the stock market crash and global financial crisis have impact on interbank call rate return but not on its volatility. The stock market crash and global financial crisis could have accounted for the sudden change in variance. The augmented TS-GARCH $(1,1)$ model is found to be the best model.
\end{abstract}

Keywords: Interbank call rate, Stock market crash, Global Financial crisis, Volatility persistence, GARCH

JEL: G01, G11, G12, G14, G21

\section{Introduction}

The deregulation of the Nigerian financial environment following the introduction of the Structural Adjustment Programme (SAP) in Nigeria in September 1986 led to the increasing competition in the Nigerian banking industry, and the interbank market. The interbank market is the market for unsecured wholesale short term funds between banks. Bank lends and borrows in this market to smooth out its liquidity position so as to comply with statutory requirement placed on them. The major proportion of the dealing in this market is for very short term funds, i.e., overnight funds, and up to 3 months. However, some inter bank loans are for longer periods (up to one year). Interest rates are quoted for overnight or call money, 7 days' notice of withdrawal, 30 days, 60 days, 90 days, 180 days, 270 days and 360 days.

The volatility of interbank call or overnight rates has been of concern to investors, analysts, brokers, dealers and regulators as the overnight or call funds constitute the bulk of the activities in the Nigerian money market. Market participants determine the interbank call rate according to their perceptions of the current and future liquidity condition in the market. Thus this rate reflects the supply and demand behavior of bank reserves, and gives important signals to the Central bank of Nigeria (CBN) to understand the market pressure. The interbank call rate also has a close link with other interest rates in the financial market and the foreign exchange rate. Interbank call rate volatility which represents the variability of interbank call rate changes which could be perceived as a measure of uncertainty of the interbank call rate shows how much economic behaviors are not able to perceive the directionality of the actual or future volatility of interbank call rate. Central banks conduct monetary policy in such a way that the interbank call rate does not deviate much from the central bank's monetary policy rate.

Financial assets volatility of has been of growing area of research (see Longmore and Robinson (2004) among others). The variance or standard deviation and the vector autoregressive (VAR) methods are two of the common means of measuring asset volatility (see Bailey et al. (1986, 1987), Chowdhury (1993), and Arize etal. (2000)). The use of variance or standard deviation as a measure of volatility is unconditional and does not recognize that there are interesting patterns in asset volatility; e.g., time-varying and clustering properties. Researchers have introduced various models to explain and predict these patterns in volatility. .Engle (1982) introduced the autoregressive conditional heteroskedasticity (ARCH) to model volatility. Engle (1982) modeled the heteroskedasticity by relating the conditional variance of the disturbance term to the linear combination of the squared disturbances in the recent past. Bollerslev (1986) generalized the ARCH model by modeling the conditional variance to depend on its lagged values as well as squared lagged values of disturbance, which is called generalized autoregressive conditional heteroskedasticity (GARCH). Since the work of Engle (1982) and Bollerslev (1986), various variants of GARCH model have been developed to model volatility. Some of the models include IGARCH originally proposed by Engle and Bollerslev (1986), GARCH-in-Mean (GARCH-M) model introduced by Engle, Lilien and Robins (1987), the standard deviation GARCH model introduced by Taylor (1986) and Schwert (1989), the EGARCH or Exponential GARCH model proposed by Nelson (1991), TARCH or Threshold ARCH and Threshold GARCH were introduced independently by Zakoïan (1994) and Glosten, Jaganathan, and Runkle (1993), the Power ARCH model generalized by Ding, Zhuanxin, C. W. J. Granger, and R. F. Engle (1993) among others.

The modeling and forecasting of interbank call rates and their volatility has important implications for many issues in economics and finance. Unlike other financial markets, few work have been done on interest rates volatility (e.g. Cyree and Winters, 2001; Edward and Susmel, 2003; Palombini, 2003; Joshi, 2004; Shahiduzzaman and Naser, 2008). 
Palombini (2003) used the GARCH model to construct and estimate the daily and hourly volatility on the Italian money market. Shahiduzzaman and Naser (2008) used the GARCH model to investigate the pattern of volatility in the overnight money market rate (call money rate) in Bangladesh. Their results show that volatility shocks are quite persistent as the sum of ARCH and GARCH coefficients are close to one.

The interbank call rate volatility has implications for many issues in the arena of finance and economics. Such issues include impact of interbank call rate volatility on derivative pricing, other money market rates, repurchase agreement, reverse repo, open buy back, exchange rate determination in the foreign exchange market, bank's cost of funds, lending rates, and stock market and government policy decisions.

The recapitalization of the banking industry in Nigeria in July 2004 and the Insurance industry in September 2005 boosted the number of securities on Nigerian stock market increasing public awareness and confidence about the Stock market. The banking industry boosted the trading activity on the stock market through margin lending to various investors. The margin lending rate, like other interest rates, is closely linked to interbank call rates. However, since April 1, 2008, investors have been worried about the falling stock prices on the Nigerian stock market. The falling prices on the stock market could have affected interbank call money rate volatility.

The global financial crisis of 2008, an ongoing major financial crisis, could have affected interbank call rate volatility. The crisis which was triggered by the subprime mortgage crisis in the United States became prominently visible in September 2008 with the failure, merger, or conservatorship of several large United States-based financial firms exposed to packaged subprime loans and credit default swaps issued to insure these loans and their issuers (Wikipedia, 2009). The crisis rapidly evolved into a global credit crisis, deflation and sharp reductions in shipping and commerce, resulting in a number of bank failures in Europe and sharp reductions in the value of equities (stock) and commodities worldwide(Wikipedia, 2009). In the United States, 15 banks failed in 2008, while several others were rescued through government intervention or acquisitions by other banks (Wikipedia, 2009). The financial crisis created risks to the broader economy which made central banks around the world to cut interest rates and various governments implement economic stimulus packages to stimulate economic growth and inspire confidence in the financial markets. The financial crisis dramatically affected the global stock markets. Many of the world's stock exchanges experienced the worst declines in their history, with drops of around $10 \%$ in most indices (Wikipedia, 2009). In the US, the Dow Jones industrial average fell 3.6\%, not falling as much as other markets. The economic crisis caused countries to temporarily close their markets (Wikipedia, 2009).

The purpose of this paper is to model daily interbank call rate volatility in Nigeria using GARCH model in the light of stock market crash and the global financial crisis. The paper will investigate the volatility persistence in Nigeria using daily interbank call rate data. The rest of this paper is organised as follows: Section two discusses an overview of the Nigerian foreign exchange market while Section three discusses the literature review. Section four discusses methodology while the results are presented in Section five. Concluding remarks are presented in Section six.

\section{Overview of the Nigerian Money Market}

The Nigerian money markets consist of the Government Securities market, non-government Securities market, the Discount market; the Foreign Exchange market; and the Inter bank market. The government securities include treasury bills, treasury certificates, CBN bills and Eligible development stocks. Non-government securities include certificates of deposit, commercial paper, banker's acceptances and tenured deposits. The discount market promotes market in treasury bills and other eligible bills used in open market operation. The foreign exchange market is the market for buying and selling of foreign currencies. The interbank market is a market for buying and selling of unsecured wholesale short term funds, money market securities and foreign currencies between banks. The market also includes markets for repurchase agreement, reverse repo and open buyback. The major proportion of the dealing in the Nigerian interbank market is for very short term funds, i.e., overnight funds, and up to 3 months. However, some inter bank loans are for longer periods (up to one year). Interest rates are quoted for overnight money, 7 days' notice of withdrawal, 30 days, 60 days, 90 days, 180 days, 270 days and 360 days.

The inter-bank market is regulated by the Money Market Association of Nigeria (a self-regulating organisation). At the interbank market, the interest rate charged in the largest market is the Nigerian Inter-Bank Offer Rate or NIBOR, which is used by individual banks to establish their own base rate and interest rates for 'wholesale' lending to large borrowers. Lending by banks to their own customers might be at a certain rate above their base rate (retail lending) or a certain rate above the NIBOR (wholesale lending).

Prior to the deregulation of the Nigerian economy in September 1986, there were 40 banks with 1,397 branches operating in Nigeria, consisting of 28 commercial banks with 1,367 branches and 12 merchant banks with 30 branches (Olowe, 1996). The introduction of structural adjustment programme in Nigeria led to the deregulation of licensing of banks and interest rate in 1987. Prior to 1987, the level and structure of interest rates were administratively determined by the Central Bank of Nigeria. Both deposit and lending rates were fixed by the CBN based on policy decisions. There was also little activity in the interbank market during this period. However, in August 1987, within the general framework of deregulating the economy following the introduction of structural adjustment programme in 1986 to enhance competition and allocation of resources, the CBN introduced a market-based interest rate policy. The deregulation of interest rates allowed banks to determine their deposit and 
lending rates according to market condition through negotiation with their customers. As at the end of 1993, the number of commercial banks has increased to 66 with 2,353 branches while the number of merchant banks has increased to 54 with 126 branches (Central Bank of Nigeria, 1994). By 1998, however, the number of banks in operation declined to 89 as a result of the liquidation of over 30 terminally distressed banks. Other types of financial institutions also increased substantially. Apart from commercial and merchant banks, new banking institutions and other financial intermediaries have sprung up. As at the end of 1993, there were 252 primary mortgage institutions, 879 community banks, 271 Peoples bank branches, 5 development banks, 752 finance companies and 3 discount houses operating in Nigeria (Central Bank of Nigeria, 1994). The increased competition in the Nigerian financial system led to increase in activities in the Nigerian interbank market.

In June 1993, the CBN commenced open market operations (OMO) using existing government securities (treasury bills and certificates, and development stocks). The operations are coordinated with discount window and reserve requirement policies. To facilitate $\mathrm{OMO}$ and promote the growth, efficiency and development of the Nigerian money market, discount houses are now being licensed by the CBN. As at the end of 1993, 3 discount houses have been licensed (Central Bank of Nigeria, 1994).

The licensing of discount houses further promoted the activities in the interbank market. The introduction of universal banking in Nigeria in 2001 further enhanced the activities in the interbank market.

The Central Bank of Nigeria (CBN) on July 6, 2004, proposed reforms of the banking sector in Nigeria. The key element of the reforms is the increase in minimum capitalization for all licensed banks from N2 billion (approximately \$15million) to N25billion (approximately \$250million). This led to the emergence of 25 strong banking groups by December 31, 2005 (Olowe, 2009). In September 2005, the Federal Government of Nigeria announced new capital requirements for insurance companies in Nigeria. The share capital for Life business was increased to N2 billion while the share capital of Non-Life, Reinsurance and composite companies were increased to N3 billion, N10 billion and N5 billion respectively. As at February 2007, licensed, insurance companies consist of 7 Life insurance companies, 23 General insurance companies, 11 composite companies and 1 Reinsurance company (Olowe, 2009). The introduction of the new capital requirements for banks in 2004 and insurance companies in 2005 increase number of securities on the Nigerian stock market and increase the volume of trading activities on the stock market through increase in public awareness about the stock market. The banking industry further enhanced securities trading through provision of margin lending to various investors. The margin lending further enhanced the activities in the interbank market.

Figure 1 shows the trend in the call rates and open buy back (OBB) rates from June 11, 2007 to May 20, 2009. This period coincided with the completion of the recapitalization exercise in the banking and insurance industry. The call rates appear to show more fluctuations. It will be of interest to investigate the volatility of interbank call rates.

\section{Literature Review}

The variance or standard deviation and the vector autoregressive (VAR) methods are two of the common means of measuring asset volatility (see Bailey et al. (1986, 1987), Chowdhury (1993), and Arize etal. (2000)). The use of variance or standard deviation as a measure of volatility is unconditional and does not recognize that there are interesting patterns in asset volatility; e.g., time-varying and clustering properties. Researchers have introduced various models to explain and predict these patterns in volatility. .Engle (1982) introduced the autoregressive conditional heteroskedasticity (ARCH) to model volatility. Engle (1982) modeled the heteroskedasticity by relating the conditional variance of the disturbance term to the linear combination of the squared disturbances in the recent past. Bollerslev (1986) generalized the ARCH model by modeling the conditional variance to depend on its lagged values as well as squared lagged values of disturbance, which is called generalized autoregressive conditional heteroskedasticity (GARCH). This simple and useful GARCH is the dominant model applied to financial time series analysis by the parsimony principle. GARCH $(1,1)$ model can be summarized as follows:

$$
\begin{aligned}
& \mathrm{s}_{\mathrm{t}}=\mathrm{b}_{0}+\varepsilon_{\mathrm{t}} \varepsilon_{\mathrm{t}} / \mathrm{j}_{\mathrm{t}-1} \sim \mathrm{N}\left(0, \sigma_{\mathrm{t}}^{2}\right) \\
& \sigma_{\mathrm{t}}^{2}=\omega+\sum_{\mathrm{i}=1}^{\mathrm{p}} \alpha_{\mathrm{i}} \varepsilon_{\mathrm{t}-\mathrm{i}}^{2}+\sum_{\mathrm{j}=1}^{\mathrm{q}} \beta_{\mathrm{j}} \sigma_{\mathrm{t}-\mathrm{j}}^{2}
\end{aligned}
$$

where, $\sigma^{2}$ is conditional variance of $\varepsilon_{t}$ and $\omega>0, \alpha \geq 0, \beta \geq 0$. Equation (2) shows that the conditional variance is explained by past shocks or volatility (ARCH term) and past variances (the GARCH term). Equation (2) will be stationary if the persistent of volatility shocks, $\sum_{i=1}^{p} \alpha_{i}+\sum_{j=1}^{q} \beta_{j}$ is lesser than 1 and in the case it comes much closer to 1 , volatility shocks will be much more persistent. As the sum of $\alpha$ and $\beta$ becomes close to unity, shocks die out rather slowly (see Bollerslev (1986)). To complete the basic ARCH specification, we require an assumption about the conditional distribution of the error term. There are three assumptions commonly employed when working with ARCH models: normal (Gaussian) distribution, Student's $t$-distribution, and General Error Distribution. Bollerslev $(1986,1987)$, Engle and Bollerslev (1986) suggest that $\operatorname{GARCH}(1,1)$ is adequate in modeling conditional variance. 
The GARCH model has a distinctive advantage in that it can track the fat tail of asset returns or the volatility clustering phenomenon very efficiently (Yoon and Lee, 2008). The normality assumption for the error term in (1) is adopted for most research papers using ARCH. However, other distributional assumptions such as Student's $t$-distribution and General error distribution can also be assumed. Bollerslev (1987) claimed that for some data the fat-tailed property can be approximated more accurately by a conditional Students-distribution.

A weakness of the GARCH model is that the conditional variance is merely dependent on the magnitude of the previous error term and is not related to its sign. It does not account for skewness or asymmetry associated with a distribution. Thus, GARCH model can not reflect leverage effects, a kind of asymmetric information effects that have more crucial impact on volatility when negative shocks happen than positive shocks do (Yoon and Lee, 2008).

Because of this weakness of GARCH model, a number of extensions of the GARCH (p, q) model have been developed to explicitly account for the skewness or asymmetry. The popular models of asymmetric volatility includes, the exponential GARCH (EGARCH) model, Glosten, Jogannathan, and Rankle (1992) GJR-GARCH model, asymmetric power ARCH (APARCH), Zakoian (1994) threshold ARCH (TARCH). The TS-GARCH advanced by Taylor (1986) and Schwert (1990), Ding, Zhuanxin, C. W. J. Granger, and R. F. Engle (1993) generalized power ARCH model, the generalized version of Higgins and Bera (1992) non-linear ARCH (NGARCH) among others.

The TS-GARCH model developed by Taylor (1986) and Schwert (1990) is a popular model used to capture the information content in the thick tails, which is common in the return distribution of speculative prices. The specification of this model is based on standard deviations and is as follows:

$$
\sigma_{\mathrm{t}}=\omega+\sum_{\mathrm{i}=1}^{\mathrm{p}} \alpha_{\mathrm{i}}\left|\varepsilon_{\mathrm{t}-\mathrm{i}}\right|+\sum_{\mathrm{j}=1}^{\mathrm{q}} \beta_{\mathrm{j}} \sigma_{\mathrm{t}-\mathrm{j}}
$$

The exponential GARCH (EGARCH) model advanced by Nelson (1991) is the earliest extension of the GARCH model that incorporates asymmetric effects in returns from speculative prices. The EGARCH model is defined as follows:

$$
\log \left(\sigma_{\mathrm{t}}^{2}\right)=\omega+\sum_{\mathrm{i}=1}^{\mathrm{p}} \alpha_{\mathrm{i}}\left|\frac{\varepsilon_{\mathrm{t}-\mathrm{i}}}{\sigma_{\mathrm{t}-\mathrm{i}}}-\sqrt{\frac{2}{\pi}}\right|+\sum_{\mathrm{j}=1}^{\mathrm{q}} \beta_{\mathrm{j}} \log \left(\sigma_{\mathrm{t}-\mathrm{j}}^{2}\right)+\sum_{\mathrm{k}=1}^{\mathrm{r}} \gamma_{\mathrm{k}} \frac{\varepsilon_{\mathrm{t}-\mathrm{k}}}{\sigma_{\mathrm{t}-\mathrm{k}}}
$$

where $\omega, \alpha_{\mathrm{i}}, \beta_{\mathrm{j}}$ and $\gamma_{\mathrm{k}}$ are constant parameters. The EGARCH (p, q) model, unlike the GARCH (p, q) model, indicates that the conditional variance is an exponential function, thereby removing the need for restrictions on the parameters to ensure positive conditional variance. The asymmetric effect of past shocks is captured by the $\gamma$ coefficient, which is usually negative, that is, cetteris paribus positive shocks generate less volatility than negative shocks (Longmore and Robinson, 2004). The leverage effect can be tested if $\gamma<0$. If $\gamma \neq 0$, the news impact is asymmetric.

The asymmetry power ARCH (APARCH) model of Ding, Granger and Engle (1993) also allows for asymmetric effects of shocks on the conditional volatility. Unlike other GARCH models, in the APARCH model, the power parameter of the standard deviation can be estimated rather than imposed, and the optional $\gamma$ parameters are added to capture asymmetry of up to order $r$. The $\operatorname{APARCH}(\mathrm{p}, \mathrm{q})$ model is given as:

$$
\sigma_{t}^{\delta}=\omega+\sum_{i=1}^{p} \alpha_{i}\left(\left|\varepsilon_{t-i}\right|-\gamma_{i} \varepsilon_{t-i}\right)^{\delta}+\sum_{j=1}^{q} \beta_{j} \sigma_{t-j}^{\delta}
$$

where $\delta>0,\left|\gamma_{\mathrm{i}}\right| \leq 1$ for $\mathrm{i}=1, \ldots, \mathrm{r}, \gamma_{\mathrm{i}}=0$ for all $\mathrm{I}>\mathrm{r}$, and $\mathrm{r} \leq \mathrm{p}$

If $\gamma \neq 0$, the news impact is asymmetric.

The introduction and estimation of the power term in the APARCH model is an attempt to account for the true distribution underlying volatility. The idea behind the introduction of a power term arose from the fact that, the assumption of normality in modeling financial data, which restricts $d$ to either 1 or 2 , is often unrealistic due to significant skewness and kurtosis(Longmore and Robinson, 2004).. Allowing $d$ to take the form of a free parameter to be estimated removes this arbitrary restriction.

Various family of GARCH models have been applied in the modeling of the volatility of interbank call rates in various countries. Taylor (1987) and more recently West and Chow (1995) examined the forecast ability of interbank call rate volatility using a number of models including ARCH using five U.S. bilateral interbank call rate series. They found that generalized ARCH (GARCH) models were preferable at a one week horizon, whilst for less frequent data, no clear victor was evident. Yoon and Lee $(2008)$ used GARCH $(1,1)$, TARCH $(1,1)$ and EGARCH $(1,1)$ models to estimate the volatility and asymmetry of the daily Won/Dollar interbank call rate over the period, March 2, 1998 to 
June 30,2006 . Their results show that strong volatility persistence, asymmetry and leverage effect, which explain that volatility shock has an effect on the uncertainty of the interbank call rate.

Unlike other financial markets, few work have been done on interest rates volatility (e.g. Campbell, Lo, \& MacKinlay, 1997; Cyree and Winters, 2001; Palombini, 2003; Joshi, 2004; Shahiduzzaman and Naser, 2008). The earlier empirical work focused attention on investigating the time series properties of interest rate level at a daily frequency (e.g. Campbell, 1987; Hamilton, 1996) or focuses on the "liquidity effect", i.e. changes in interest rates triggered by a variation in monetary base, and the related "martingale hypothesis" (e.g. Hamilton, 1997; Bartolini, Bertola and Prati, 2000). Palombini (2003) used the GARCH model to construct and estimate the daily and hourly volatility on the Italian money market.

Shahiduzzaman and Naser (2008) used the GARCH model to investigate the pattern of volatility in the overnight money market rate (call money rate) in Bangladesh. Their results show that volatility shocks are quite persistent as the sum of ARCH and GARCH coefficients are close to one.

Little or no work has been done on modeling interbank call rate volatility in Nigeria particularly using GARCH models. This study will model the volatility of interbank call rates in Nigeria using daily data in the light of stock market crash and. global financial crisis.

\section{Methodology}

\subsection{The Data}

The time series data used in this analysis consists of the daily interbank call rate from June 11, 2007 to May 20, 2009 downloaded from the website of the Central Bank of Nigeria. As in previous work on interest rate volatility, the focus will on first difference (see, for example, Gray, 1996; Ghysels \& Ng, 1998; and Edwards and Susmel, 2003). Concentrating on changes in interest rates avoids the problems associated with series that have a large, possibly unit root. Thus, in this study, the return on interbank call rate series is defined as:

$$
r_{t}=I_{t}-I_{t-1}
$$

Where $r_{t}$ represents return on interbank call rate series at time $t$;

$\mathrm{I}_{\mathrm{t}}$ represent interbank call rate at time $\mathrm{t}$.

$\mathrm{I}_{\mathrm{t}-1}$ represent interbank call rate at time $\mathrm{t}-1$.

The $r_{t}$ of Equation (1) will be used in investigating the volatility of interbank call rate in Nigeria over the period, June 11, 2007 to May 20, 2009.

However, since April 1, 2008, investors have been worried about the falling stock prices on the Nigerian stock market. The falling prices on the stock market could have affected interbank call money rate volatility.

Since April 1, 2008, investors have been worried about the falling stock prices on the Nigerian stock market. The stock index fell from 63016.56 on April 1, 2008 to 27108.4 on January 16, 2009. The falling prices on the stock market could have affected interbank call money rate volatility. To account for the stock market crash (SMC) in this paper, a dummy variable is set equal to 0 for the period before April 1,2008 and 1 thereafter.

The global financial crisis of 2008 , an ongoing major financial crisis, was triggered by the subprime mortgage crisis in the United States which became prominently visible in September 2008 with the failure, merger, or conservatorship of several large United States-based financial firms exposed to packaged subprime loans and credit default swaps issued to insure these loans and their issuers (Wikipedia, 2009). On September 7, 2008, the United States government took over two United States Government sponsored enterprises Fannie Mae (Federal National Mortgage Association) and Freddie Mac (Federal Home Loan Mortgage Corporation) into conservatorship run by the United States Federal Housing Finance Agency. The two enterprises as at then owned or guaranteed about half of the U.S.'s $\$ 12$ trillion mortgage market. This causes panic because almost every home mortgage lender and Wall Street bank relied on them to facilitate the mortgage market and investors worldwide owned $\$ 5.2$ trillion of debt securities backed by them (Wikipedia, 2009). Later in that month Lehman Brothers and several other financial institutions failed in the United States. This crisis rapidly evolved to global crisis. In this study, September 7, 2008 is taken as the date of commencement of the global financial crisis. To account for global financial crisis (GFC) in this paper, a dummy variable is set equal to 0 for the period before September 7, 2008 and 1 thereafter.

\subsection{Properties of the Data}

The summary statistics of the interbank call rate return series is given in Table 1 . The mean return is 0.0002 while the standard deviation is 0.0173 . The skewness for the interbank call rate return series is -1.1346 . This shows that the distribution, on average, is negatively skewed relative to the normal distribution ( 0 for the normal distribution). The skewness indicates a non-symmetric series. The kurtosis is much larger than 3 , the kurtosis for a normal distribution. Skewness indicates non-normality, while the excess kurtosis suggests that distribution of the return series is leptokurtic, signaling the necessity of a peaked distribution to describe this series. This suggests that for the interbank call rate return series, large market surprises of either sign are more likely to be observed, at least unconditionally. The Ljung-Box test Q statistics for the interbank call rate return series are, on average, insignificant at the $5 \%$ for all reported lags confirming the absence of autocorrelation in interbank call rate return series. 
Jarque-Bera normality test rejects the hypothesis of normality for the interbank call rate return series. Figure 2 shows the quantile-quantile plots of the interbank call rate returns for the period. Figure 2 shows that the distribution of the interbank call rate returns series show a strong departure from normality.

The usual method of testing for testing for conditional homoscedasticity by calculating the autocorrelation of the squared return series might not be appropriate here in view of the non-normality of the interbank call rate return series (see Mckenzie (1997)). According to Mckenzie (1997), volatility clustering is by no means unique to the squared returns of an assets price. In general, the absolute changes in an assets price will exhibit volatility clustering and the inclusion of any power term acts so as to emphasise the periods of relative tranquility and volatility by highlighting the outliers in that series. It is possible to specify any power term to complete this task from a myriad of options inclusive of any positive value (Mckenzie, 1997). The common use of a squared term is most likely a reflection of the normality assumption made regarding the data. If a data series is normally distributed, then we are able to completely characterise its distribution by its first two moments. As such, it may be appropriate to focus on a squared term. However, if we accept that the data has a non-normal error distribution, then one must transcend into the realm of the higher moments of skewness and kurtosis to adequately describe the data. In this instance, the intuitive appeal of a squared term is lost and other power transformations may be more appropriate (Mckenzie, 1997). Following, Mckenzie (1997), the test for conditional homoscedasticity was carried out by calculating the autocorrelation of power transformed interbank call rate return series using powers of 0.25 and 0.5 . The Ljung-Box $Q^{0.25}$ and $Q^{0.5}$ statistics for the interbank call rate return series are significant at the $5 \%$ for all reported lags confirming the presence of heteroscedasticity in the data.

Table 2 shows the results of unit root test for the interbank call rate return series. The Augmented Dickey-Fuller test and Phillips-Perron test statistics for the interbank call rate return series are less than their critical values at the $1 \%, 5 \%$ and $10 \%$ level. This shows that the interbank call rate return series has no unit root. Thus, there is no need to difference the data.

In summary, the analysis of the interbank call rate return indicates that the empirical distribution of returns in the call money market is non-normal, with very thick tails. The leptokurtosis reflects the fact that the market is characterised by very frequent medium or large changes. These changes occur with greater frequency than what is predicted by the normal distribution. The empirical distribution confirms the presence of a non-constant variance or volatility clustering. Volatility clustering is apparent in Figure 3. This implies that volatility shocks today influence the expectation of volatility many periods in the future.

\subsection{Models used in the Study}

In the light of volatility clustering in the empirical distribution of interbank call rate return series, this study will attempt to model the volatility of daily interbank call rate return in Nigeria using the GARCH, EGARCH, TS-GARCH and PARCH models in the light of stock market crash and the global financial crisis. The various families of GARCH models will be used so that the sensitivity of the results to the various GARCH models can be assessed. The best model will be the one that has maximum log-likelihood and/or lowest Akaike information Criterion or Schwarz Criterion or Hannan-Quinn criterion. The GARCH $(1,1)$ model will first be applied in investigating the volatility of the interbank call rate return series. Then, the $\operatorname{GARCH}(1,1), \operatorname{EGARCH}(1,1)$, TS-GARCH $(1,1)$ and $\operatorname{PARCH}(1,1)$ models will be augmented to account for sudden change in variance in the volatility equation.

Thus, the mean and variance equations of the $\operatorname{GARCH}(1,1)$ model are given as :

$$
\begin{aligned}
& \mathrm{R}_{\mathrm{t}}=\mathrm{b}_{0}+\mathrm{b}_{1} \mathrm{SMC}+\mathrm{b}_{2} \mathrm{GFC} \varepsilon_{\mathrm{t}} / \mathrm{j}_{\mathrm{t}-1} \sim \operatorname{GED}\left(0, \sigma_{\mathrm{t}}^{2}, \mathrm{r}\right) \\
& \sigma_{\mathrm{t}}^{2}=\omega+\alpha \varepsilon_{\mathrm{t}-1}^{2}+\beta \sigma_{\mathrm{t}-1}^{2}
\end{aligned}
$$

where $\mathrm{v}_{\mathrm{t}}$ is the degree of freedom

To account for the shift in variance as a result of the stock market crash and global financial crisis, the GARCH(1,1) model is re-estimated with the mean equation (7) while the variance equation is augmented as follows:

$$
\sigma_{\mathrm{t}}^{2}=\omega+\alpha \varepsilon_{\mathrm{t}-1}^{2}+\beta \sigma_{\mathrm{t}-1}^{2}+\Theta_{1} \mathrm{SMC}+\Theta_{2} \mathrm{GFC}
$$

To enable comparison with other models and to allow for possible asymmetric and leverage effects, the GARCH model of Equation (8) accounting for the shift in variance as a result of the stock market crash and global financial crisis is restimated using is using other volatility models as follows:

$$
\begin{gathered}
\operatorname{EGARCH}(1,1): \log \left(\sigma_{\mathrm{t}}^{2}\right)=\omega+\alpha\left|\frac{\varepsilon_{\mathrm{t}-1}}{\sigma_{\mathrm{t}-1}}-\sqrt{\frac{2}{\pi}}\right|+\beta \log \left(\sigma_{\mathrm{t}-1}^{2}\right)+\gamma\left|\frac{\varepsilon_{\mathrm{t}-1}}{\sigma_{\mathrm{t}-1}}\right|+\Theta_{1} \mathrm{SMC}+\Theta_{2} \mathrm{GFC} \\
\text { TS-GARCH}(1,1): \sigma_{\mathrm{t}}=\omega+\alpha\left|\varepsilon_{\mathrm{t}-1}\right|+\beta \sigma_{\mathrm{t}-1}+\Theta_{1} \mathrm{SMC}+\Theta_{2} \mathrm{GFC}
\end{gathered}
$$




$$
\operatorname{PARCH}(1,1): \sigma_{\mathrm{t}}^{\delta}=\omega+\alpha\left(\left|\varepsilon_{\mathrm{t}-1}\right|-\gamma \varepsilon_{\mathrm{t}-1}\right)^{\delta}+\beta \sigma_{\mathrm{t}-1}^{\delta}+\Theta_{1} \mathrm{SMC}+\Theta_{2} \mathrm{GFC}
$$

The mean equation is the same as in Equation (8). The volatility parameters to be estimated include $\omega, \alpha$ and $\beta$. As the interbank call rate return series shows a strong departure from normality, all the models will be estimated with Generalised Error Distribution as the conditional distribution for errors. The estimation will be done in such a way as to achieve convergence.

\section{The Results}

The results of estimating the GARCH models as stated in Section 4.3 are presented in Table 4 . In the mean equation, the coefficient $b_{1}$ and $b_{2}$ representing coefficients of the stock market crash and global financial crisis respectively, are all statistically significant at the 5\% level in the GARCH $(1,1)$ model and all the augmented models. This implies that the stock market crash and global financial crisis have impact on interbank call rate returns.

The variance equation in Table 4 shows that the coefficients are positive and statistically significant at the $5 \%$ level in the GARCH $(1,1)$ model and all the augmented models except augmented GARCH $(1,1)$ model. However, the coefficient in the augmented GARCH $(1,1)$ model is significant at the $10 \%$ level. This confirms that the ARCH effects are very pronounced implying the presence of volatility clustering. Conditional volatility tends to rise (fall) when the absolute value of the standardized residuals is larger (smaller) (Leon, 2007).

Table 3 shows that the $\beta$ coefficients (the GARCH parameter) are statistically significant in the GARCH(1,1) model and all the augmented models. The sum of the

$\alpha$ and $\beta$ coefficients in the in the $\operatorname{GARCH}(1,1)$ model, augmented $\operatorname{GARCH}(1,1)$ model and augmented TS-GARCH $(1,1)$ model are $0.9886,0.8977$ and 0.8625 respectively. This appears to show that there is high persistence in volatility as the sum of $\alpha$ and $\beta$ are, on average, close to 1 in the GARCH(1,1) model, augmented GARCH(1,1) model and augmented TS-GARCH(1,1) model. In the augmented EGARCH(1,1) models of Table $4, \beta$ is 0.6169 showing persistent volatility in the EGARCH model. In the augmented PARCH models of Tables $4, \alpha+\beta$ $+(\gamma / 2)$ is 0.8679 which is also close to 1 . This also appears to show that the shocks to volatility are very high under the PARCH model.

Table 4 shows that the coefficients $\gamma$, the asymmetry and leverage effects, is positive and statistically insignificant at the 5\% level in the augmented EGARCH model; and negative and statistically insignificant in the augmented PARCH model. However, leverage effect will only exist if $\gamma>0$ in the PARCH model and $\gamma<0$ in the EGARCH. In view of the signs and statistically insignificance of $\gamma$ in the EGARCH and PARCH models, the hypothesis of asymmetry and leverage effect is rejected for the augmented EGARCH $(1,1)$ and augmented PARCH $(1,1)$ models.

The stock market crash and global financial crisis could have accounted for sudden changes in variance. The augmented GARCH models where the stock market crash and global financial crisis variables are added to variance equation indicates that $\Theta_{1}$ and $\Theta_{2}$ representing coefficients of the stock market crash and global financial crisis respectively are all statistically insignificant at the $5 \%$ level. The volatility persistence in the augmented is higher than that of the full sample. This appears to indicate that the stock market crash and global financial crisis could have accounted for the sudden change in variance.

The estimated coefficients of the GED parameter are significant at the 5-percent level in the GARCH(1,1) model and all the augmented models implying the appropriateness of Generalised error distribution.

\subsection{Diagnostic Checks}

Table 4 shows the results of the diagnostic checks on the estimated GARCH(1,1) model and all the augmented models. Table 5 shows that the Ljung-Box Q-test statistics of the standardized residuals for the remaining serial correlation in the mean equation shows that autocorrelation of standardized residuals are statistically insignificant at the $5 \%$ level in the GARCH $(1,1)$ model and all the augmented models confirming the absence of serial correlation in the standardized residuals. This shows that the mean equations are well specified. The Ljung-Box $\mathrm{Q}^{2}$-statistics of the squared standardized residuals in Table 5 are all insignificant at the $5 \%$ level in the GARCH $(1,1)$ model and all the augmented models confirming the absence of ARCH in the variance equation. The ARCH-LM test statistics in Table 5 for the GARCH $(1,1)$ model and all the augmented models further showed that the standardized residuals did not exhibit additional ARCH effect. This shows that the variance equations are well specified in the $\operatorname{GARCH}(1,1)$ model and all the augmented models. The Jarque-Bera statistics still shows that the standardized residuals are not normally distributed. In sum, all the models are adequate for forecasting purposes. The volatilities for the GARCH $(1,1)$ model, augmented $\operatorname{GARCH}(1,1)$ model, augmented $\operatorname{EGARCH}(1,1)$ model, augmented TS-GARCH(1,1) model and the augmented PARCH $(1,1)$ models are plotted in Figures 4,5,6,7 and 8 respectively showing their conditional standard deviation.

\section{Conclusion}

This paper investigated the volatility of daily interbank call rates in Nigeria using GARCH $(1,1), \operatorname{EGARCH}(1,1)$, TS-GARCH $(1,1)$ and PARCH $(1,1)$ models in the light of stock market crash and global financial crisis. Volatility persistence and asymmetric properties are investigated for the Nigerian interbank call money market. The result also 
shows that volatility is persistent. The hypothesis of asymmetry and leverage effect is rejected. It is found that the Nigerian interbank call money market returns show high persistence in the volatility but it shows clustering properties. The result shows the stock market crash and global financial crisis have impact on interbank call rate return but not on its volatility. The stock market crash and global financial crisis could have accounted for the sudden change in variance. The augmented TS-GARCH(1,1) model is found to be the best model.

The high volatility persistence could be due to liquidity crisis caused by the stock market crash and global financial crisis. It appears the stock market of emerging markets is integrated with the global financial market. The financial crisis in the developed markets could have affected the emerging markets. It is suspected that the sub mortgage crisis in the United States which causes liquidity crisis could have put up pressure on foreign investors in the Nigerian and other emerging stock market to sell off their shares so as to provide the needed cash to address their financial problems. The continuous sale of shares by foreign investors causes the stock prices to fall in the Nigerian stock market. The fall in stock prices resulted in the loss of investor's confidence leading to further decline as many banks that granted credit facilities for stock trading recall their loans. In the process many banks suffered huge losses as a result of the margin loans they granted for stock trading. The huge losses suffered by banks along with withdrawal of foreign investments in the country exerted pressure on liquidity of banks, thus, putting pressure on the interbank call money market. Another possible cause of high volatility in the interbank call money market is the continuous sourcing of funds by banks to enable them bid for foreign exchange at the foreign exchange market. There is a need for regulators in the emerging markets to evolve policy towards the stability and restoration of investor's confidence in the Nigerian stock market. Governments should possibly aid the promotion of market makers towards warehousing shares and creating the market for securities trading. This will go a long way in reducing losses of banks. The Central Bank of Nigeria should continue to monitor all foreign exchange bidding by banks to ensure that they are genuine demand for foreign exchange by users of foreign exchange. Proper monitoring of purchase and sale of foreign exchange by banks will reduce pressure on bank's liquidity.

\section{References}

Allen, C., \& Robinson, W. (2004). Monetary Policy Rules and the Transmission Mechanism in Jamaica. Working Paper, Bank of Jamaica.

Asseery, A., \& Peel, D. (1991). The effects of exchange rate volatility on exports. Economic Letters, 37,173-177

Arize, A., Thomas, O., \& Slottje, D. (2000). Exchange-Rate volatility and foreign trade: evidence from thirteen LDC's,. Journal of Business, Economics and Statistics, 18,10-17.

Bailey, M., Tavlas, G., \& Ulan, M. (1986). 'Exchange-Rate variability and trade performance: evidence from the big seven industrial countries. Weltwirtschaftliches Archive, 122, 466-477

Bailey, M., Tavlas, G., \& Ulan, M. (1987). The impact of exchange-rate volatility on export growth: some theoretical considerations and empirical results,. Journal of Policy Model, 9, 225-243

Baillie, R. T., \& Bollerslev, T. (1989). The message in daily exchange rates: A conditional-variance tale Journal of Business and Economic Statistics, 7, 297 - 305.

Baillie, R. T., \& Bollerslev, T. (1992). Prediction in Dynamic models with Time Dependent Conditional Variances. Journal of Econometrics. 52. 91-132.

Bartolini, L., Bertola, G., \& Prati, A. (2000). Day-to-Day Monetary Policy and the Volatility of the Federal Funds Interest Rate, Journal of Money, Credit and Banking, 34, pp. 137-159.

Bollerslev, T. (1986). Generalized Autoregressive Conditional Hetroscedasticity. Journal of Econometrics, 31. 307-327.

Bollerslev, T., Chou, R. Y., \& Kroner, K. F. (1992). ARCH Modelling in Finance. Journal of Econometrics, 52, 5-59.

Bollerslev, T., \& Domowitz, I. (1993). Trading Patterns \& Prices in the Interbank Foreign Exchange Market. Journal of Finance, 48, 1421-1443.

Bollerslev, T., Engle, R. F., \& Nelson, D. B. (1994). ARCH Models. In R. F. Engle \& D. L. McFadden (Eds.), Handbook of Econometrics (Volume 4). Amsterdam: ElsevierScience B.V.

Bollerslev, T., Engle, R. F., \& Wooldridge, J. M. (1998). A Capital Asset Pricing Model with Time Varying Covariances. Journal of Political Economy, 96, 116 - 131.

Campbell, J. Y. (1987). Money Announcements, the Demand for Bank Reserves, and the Behavior of the Federal Funds Rate within the Statement Week, Journal of Money, Credit and Banking, 19, 56-67.

Caporate, T., \& Doroodian, K. (1994). Exchange rate variability and the flow of international trade. Economics Letters, 46, 49-54.

Central Bank of Nigeria. (1994). CBN Briefs on the Nigerian Financial System, Lagos, August .

Chong, C. W., Ahmad, M. I., \& Abdullah, M. Y. (1999). Performance of GARCH Models in Forecasting Stock Market Volatility. Journal of Forecasting, 18, 333-343. 
Chowdhury, A. (1993). Does exchange rate volatility depress trade flows? evidence from error-correction models, Review of Economics and Statistics, 75, 700-706

Choudhry, T. (2005). Exchange rate volatility and the united states exports: evidence from Canada and Japan, Journal of Japanese International Economics, 19, 51-71

Choudhry, T. (2008). Exchange rate volatility and United Kingdom trade: evidence from Canada, Japan and New Zealand, Empirical Economics, Springer-Verlag, DOI 10.1007

Cyree, K. B., \& Winters, D. B. (2001). Analysis of Federal Funds Rate Changes and Variance Patterns, Journal of Financial Research, 24, pp. 403-418

Dickey, D. A., \& Fuller, W.A. (1979). Distribution of the estimators for autoregressive time series with a unit root. Journal of American Statistical Association, 74, 427-431.

Ding, Z., Engle, R. F., \& Granger, C.W.J. (1993). Long Memory Properties of Stock Market Returns and a New Model. Journal of Empirical Finance, 1, 83 - 106.

Engle, R. F. (1982). Autoregressive Conditional Heteroscedasticity with Estimates of the Variance of United Kingdom Inflation. Econometrica, 50, 987-1008.

Engle, R. F., \& Kroner, K. F. (1995). Multivariate Simultaneous Generalized ARCH. Econometric Theory, 11, 1122 -150 .

Engle, R. F., Lilien, D M., \& Robins, R. P. (1987). Estimating Time Varying Risk Premia in the Term Structure: The ARCH-M Model, Econometrica, 55, 391-407.

Glosten, L. R., Jagannathan, R., \& Runkle, D. (1993). On the Relation between the Expected Value and the Volatility of the Nominal Excess Return on Stocks. Journal of Finance, 48, 1779-1801.

Gray, S. (1996). Modeling the Conditional Distribution of Interest Rates as a Regime Switching Process, Journal of Financial Economics 42, 27-62.

Ghysels, E., \& Ng, S. (1998). A Semiparametric Factor Model of Interest Rates and Tests of the Affine Term Structure, Review of Economic Statistics, 80, 535-548.

Hamilton, J. D. (1996). The Daily Market for Federal Funds, Journal of Political Economy, 104, 26-56.

Hamilton, J. D. (1997). Measuring the Liquidity Effect, American Economic Review, 87, 80-97.

Joshi, H. (2004). The Interbank Money Market in India: Evidence on Volatility, Efficacy of Regulatory Initiatives and Implications for Interest Rate Targeting, Reserve Bank of India Occasional Papers, Vol. 25, No. 1, 2 and 3.

Kim, C. M., \& Kon, S. (1994). Alternative Model of Conditional Heteroscedasticity in Stock Returns. Journal of Business, 67, 563-98.

Kroner, K., \& Lastrapes, W. (1993). The impact of exchange rate volatility on international trade: reduce from estimates using the GARCH-in-mean model, Journal of International Money and Finance, 12, 298-318

Lee J. (1999). The effects of exchange rate volatility on trade in durables,. Review of International Economics, 7,189-201

Lee, J. H. H., \& King, M. L. (1993). A Locally Most Mean Powerful Based Score Test for ARCH and GARCH Regression Disturbances Journal of Business and Economic Statistics, 11, 11 - 27.

Longmore, R., \& Robinson, W. (2004). Modelling and Forecasting Exchange Rate Dynamics: An Application of Asymmetric Volatility Models. Bank of Jamaica. Working Paper WP2004/03.

Luu, J.C. \& M. Martens. (2002). Testing the mixture of Distribution H1986. Generalized Autoregressive Conditional Hetroscedasticity. Journal of Econometrics, 31, 307-327.

Lyons, R. K. (2001). News Perspective on the FX Markets: Order Flow Analysis. International Finance.

McKenzie, M. D. (1997). ARCH Modelling of Australian Bilateral Exchange Rate Data Applied Financial Economics, 7, 147 - 164.

McKenzie, M. D. (1997). Forecasting Australian Exchange Rate Volatility : A Comparative Study of Alternate Modelling Techniques And The Impact of Power Transformations. MelBourne-Centre in Finance Papers, 97-10.

McKenzie, M . (1999). The impact of exchange rate volatility on international trade flows. Journal of Economics Survey, $13,71-106$

Mark, N. C. (1995). Exchange Rates and Fundamentals: Evidence of Long-Horizon Predictability. The American Economic Review. 85(1).201-218.

McFarlene, L. (2002). Consumer Price Inflation and Exchange Rate Pass-Through in Jamaica. Bank of Jamaica.

Meese, R. \& Rogoff, K. (1983). Empirical Exchange Rate Models of the Seventies: Do They Fit the Out of Sample? Journal of International Economics, 14, 3-24.

Meese, R. A., \& Rose, A. K. (1991) An Empirical Assessment of Nonlinearities in Models of Exchange Rate Determination Review of Economic Studies, 58, 603 -19. 
Nelson, D. B. (1990a). ARCH models as Diffusion Approximations. Journal of Econometrics, 45, 7 - 38.

Nelson, D.B. (1990b). Stationarity and Persistence in the GARCH(1,1) model Econometric Reviews, 6, 318 - 334.

Nelson, D.B. (1990c). Conditional Heteroskedasticity in Asset Returns: A new approach Econometrica, 45, 347 370 .

Nelson, D.B. (1999). Conditional Heteroskedasticity in Asset Returns : A New Approach. Econometrica, 59, 347 370.

Ng. V. R. Engle \& M. Rothschild. (1992). A Multi Dynamic Factor Model for Stock Returns. Journal of Econometrics, 52, 245 - 266.

Olowe, R. A. (1996). Determinants of Commercial Banks' Loan Rates in A Deregulated Financial Environment: the Nigerian Case, Nigeria Management Review, 10, 694-705

Olowe, R. A. (2009). Financial Management: Concepts, Financial System and Business Finance. (2 ${ }^{\text {nd }}$ edition). Lagos: Brierly Jones Nigeria.

Palombini, E. (2003). Volatility and Liquidity in the Italian Money Market, Working Paper No. 6, Marzo 2003.

Pillips, P. C. B., \& Perron, P. (1988). Testing for a Unit Root in Time Series Regression. Biometrika, 333-346.

Robinson, J., \& Robinson, W. (1997). Monetary Policy and the Jamaican Economy: A Study of the Transmission Mechanism. Bank of Jamaica.

Sanusi, J. O. (2004). Exchange Rate Mechanism: The Current Nigerian Experience.Paper Presented At A Luncheon Organised By Nigerian-British Chamber of Commerce.

Schert, G. W., \& Seguin, P. J. (1990). Heteroskedasticity in Stock Returns. Journal of Finance, 4, 1129 - 1155.

Schwert, W. (1989). Stock Volatility and Crash of '87, Review of Financial Studies, 3, 77-102.

Taylor, S. (1986). Modelling Financial Time Series. London: John Wiley \& Sons.

Taylor, S. J. (1987). Forecasting the Volatility of Currency Exchange Rates International Journal of Forecasting, 3, $159-70$.

Wikipedia. (2009). Global financial crisis of 2008-2009. [Online] Available: http://en.wikipedia.org ( February 1999).

Yoon, S. \& K. S. Lee. (2008). The Volatility and Asymmetry of Won/Dollar Exchange Rate. Journal of Social Sciences 4 (1): 7-9, 2008.

Zakoïan, J. M. (1994). Threshold Heteroskedastic Models, Journal of Economic Dynamics and Control, 18, 931-944.

\section{Appendix}

Table 1. Summary Statistics and Autocorrelation of the Interbank call rate return series over the period, June 11, 2007 - May 20, 2009

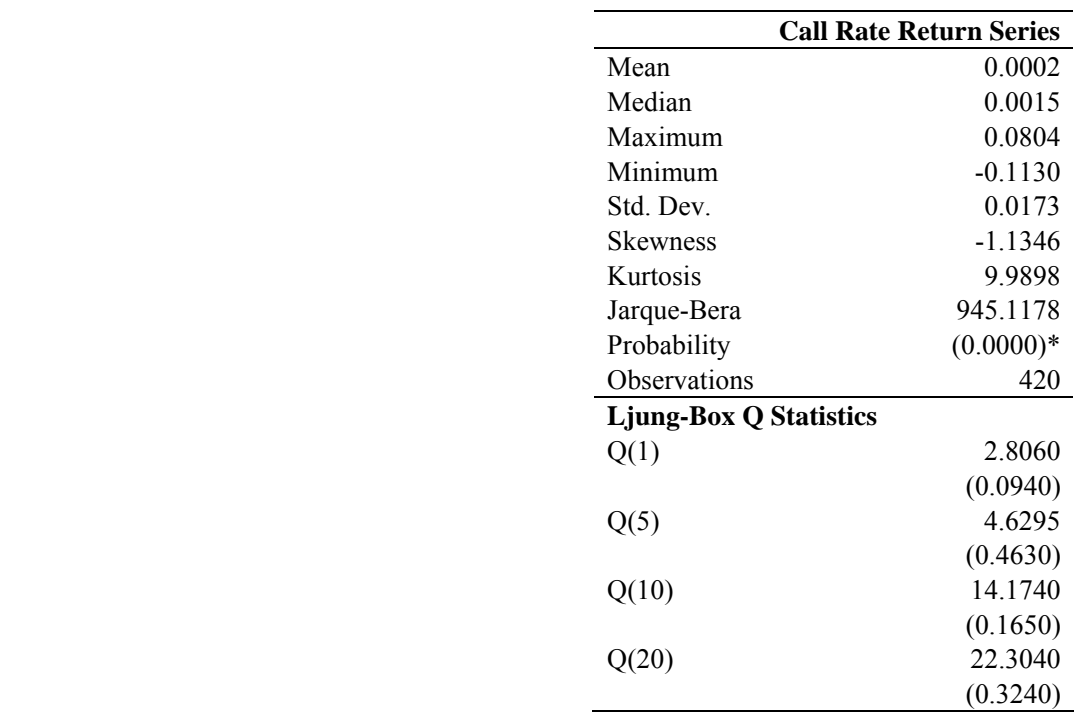

Notes:p values are in parentheses.

*indicates significance at the $5 \%$ level 
Table 2. Autocorrelation of the Interbank Call Rate Return Series over the period, June 11, 2007 - May 20, 2009

\begin{tabular}{|c|c|c|c|c|}
\hline & \multicolumn{4}{|l|}{ Lags } \\
\hline & 5 & 10 & 15 & Q20 \\
\hline \multirow[t]{2}{*}{ Ljung-Box $Q^{0.25}$ Statistics } & 17.5880 & 23.9350 & 30.2930 & 37.4940 \\
\hline & $(0.0040)^{*}$ & $(0.0080)^{*}$ & $(0.0110)^{*}$ & $(0.0100)^{*}$ \\
\hline \multirow[t]{2}{*}{ Ljung-Box $Q^{0.5}$ Statistics } & 13.5550 & 19.2740 & 26.3530 & 36.6180 \\
\hline & $(0.0190)^{*}$ & $(0.0370)^{*}$ & $(0.0340)^{*}$ & $(0.0130)^{*}$ \\
\hline
\end{tabular}

Notes:p values are in parentheses. *indicates significance at the $5 \%$ level

Table 3. Unit Root Test of the Interbank Call Rate Return Series over the period, June 11, 2007 - May 20, 2009

\begin{tabular}{lllll}
\hline & \multicolumn{3}{c}{ Statistic } & \multicolumn{3}{l}{ Critical Values } \\
\cline { 2 - 5 } & & $1 \%$ level & $5 \%$ level & $10 \%$ level \\
Augmented Dickey-Fuller test & -22.1819 & -2.5705 & -1.9416 & -1.6162 \\
Philips-Perron test & -22.7040 & -2.5705 & -1.9416 & -1.6162 \\
\hline
\end{tabular}

Notes: The appropriate lags are automatically selected employing Akaike information Criterion

Table 4. Parameter Estimates of the EGARCH-in-Mean Models January 2, 2002 - March 13, 2009

\begin{tabular}{|c|c|c|c|c|c|}
\hline & \multirow[t]{2}{*}{ GARCH $(1,1)$} & \multicolumn{4}{|c|}{ AUGMENTED MODELS } \\
\hline & & GARCH & EGARCH & TS-GARCH & PARCH \\
\hline \multicolumn{6}{|c|}{ Mean Equation } \\
\hline \multirow[t]{2}{*}{$\mathrm{b}_{0}$} & 0.0007 & 0.0007 & 0.0008 & 0.0008 & 0.0008 \\
\hline & $(0.0014)^{*}$ & $(0.0094)^{*}$ & $(0.0002)^{*}$ & $(0.0006)^{*}$ & $(0.0002)^{*}$ \\
\hline \multirow[t]{2}{*}{$\mathrm{b}_{1}$} & 0.0014 & 0.0014 & 0.0013 & 0.0013 & 0.0013 \\
\hline & $(0.0017)^{*}$ & $(0.0000)^{*}$ & $(0.0000)^{*}$ & $(0.0001)^{*}$ & $(0.0000)^{*}$ \\
\hline \multirow[t]{2}{*}{$\mathrm{b}_{2}$} & 0.0019 & 0.0018 & 0.0018 & 0.0021 & 0.0017 \\
\hline & $(0.0006)^{*}$ & $(0.0007)^{*}$ & $(0.0001)^{*}$ & $(0.0003)^{*}$ & $(0.0037)^{*}$ \\
\hline \multicolumn{6}{|c|}{ Variance Equation } \\
\hline \multirow[t]{2}{*}{$\omega$} & 0.0000 & 0.0000 & -3.7486 & 0.0031 & 0.0001 \\
\hline & $(0.1275)$ & $(0.1064)$ & $(0.0129)^{*}$ & $(0.0262)^{*}$ & $(0.8217)$ \\
\hline \multirow[t]{2}{*}{$\alpha$} & 0.1696 & 0.1583 & 0.5405 & 0.3396 & 0.2016 \\
\hline & $(0.0228)^{*}$ & $(0.0564)^{* *}$ & $(0.0022)^{*}$ & $(0.0034)^{*}$ & $(0.0435)^{*}$ \\
\hline \multirow[t]{2}{*}{$\beta$} & 0.8190 & 0.7394 & 0.6169 & 0.5229 & 0.7461 \\
\hline & $(0.0000)^{*}$ & $(0.0000)^{*}$ & $(0.0002)^{*}$ & $(0.0005)^{*}$ & $(0.0000)^{*}$ \\
\hline \multirow[t]{2}{*}{$\gamma$} & & & 0.1159 & & -0.1596 \\
\hline & & & $(0.3734)$ & & $(0.4931)$ \\
\hline \multirow[t]{2}{*}{$\delta$} & & & & & 1.6337 \\
\hline & & & & & $(0.0768)^{* *}$ \\
\hline \multirow[t]{2}{*}{$\Theta_{1}$} & & 0.0000 & 0.1768 & 0.0010 & 0.0001 \\
\hline & & $(0.1887)$ & $(0.2821)$ & $(0.2552)$ & $(0.7965)$ \\
\hline \multirow[t]{2}{*}{$\Theta_{2}$} & & 0.0000 & 0.4124 & 0.0027 & 0.0002 \\
\hline & & $(0.1564)$ & $(0.0905)$ & $(0.1167)$ & (0.7396) \\
\hline \multirow[t]{2}{*}{ GED } & 0.6022 & 0.6470 & 0.6309 & 0.6452 & 0.6538 \\
\hline & $(0.0000)^{*}$ & $(0.0000)^{*}$ & $(0.0000)^{*}$ & $(0.0000)^{*}$ & $(0.0000)^{*}$ \\
\hline Persistence & 0.9886 & 0.8977 & 0.6169 & 0.8625 & 0.8679 \\
\hline LL & 1236 & 1240 & 1242 & 1243 & 1241 \\
\hline AIC & -5.8485 & -5.8614 & -5.8667 & -5.8738 & -5.8551 \\
\hline SC & -5.7812 & -5.7749 & -5.7705 & -5.7873 & -5.7493 \\
\hline HQC & -5.8219 & -5.8272 & -5.8286 & -5.8396 & -5.8133 \\
\hline $\mathrm{N}$ & 420 & 420 & 420 & 420 & 420 \\
\hline
\end{tabular}

Notes: Standard errors are in parentheses. *indicates significant at the $5 \%$ level.

LL, AIC, SC, HQC and N are the maximum log-likelihood, Akaike information Criterion, Schwarz Criterion, Hannan-Quinn criterion and Number of observations respectively 
Table 5. Autocorrelation of Standardized Residuals, Autocorrelation of Squared Standardized Residuals and ARCH LM test for the GARCH Models over the period January 2, 2002 - March 13, 2009

\begin{tabular}{|c|c|c|c|c|c|}
\hline & \multirow[t]{2}{*}{ GARCH $(1,1)$} & \multicolumn{4}{|c|}{ AUGMENTED MODELS } \\
\hline & & GARCH & EGARCH & TS-GARCH & PGARCH \\
\hline \multicolumn{6}{|c|}{ Ljung-Box Q Statistics } \\
\hline \multirow[t]{2}{*}{$\mathrm{Q}(1)$} & 0.5973 & 1.3464 & 0.6123 & 0.7235 & 1.0376 \\
\hline & $(0.4400)$ & $(0.2460)$ & $(0.4340)$ & $(0.3950)$ & $(0.3080)$ \\
\hline \multirow[t]{2}{*}{$\mathrm{Q}(10)$} & 8.1419 & 9.0336 & 10.2990 & 10.3020 & 8.7914 \\
\hline & $(0.6150)$ & $(0.5290)$ & $(0.4150)$ & $(0.4140)$ & $(0.5520)$ \\
\hline \multirow[t]{2}{*}{$Q(15)$} & 12.8900 & 15.3050 & 16.0360 & 16.3490 & 15.5130 \\
\hline & $(0.6110)$ & $(0.4300)$ & $(0.3800)$ & $(0.3590)$ & $(0.4150)$ \\
\hline \multirow[t]{2}{*}{$\mathrm{Q}(20)$} & 18.3360 & 18.3570 & 19.0340 & 19.6100 & 18.7610 \\
\hline & $(0.5650)$ & $(0.5640)$ & $(0.5200)$ & $(0.4830)$ & $(0.5370)$ \\
\hline \multicolumn{6}{|c|}{ Ljung-Box $Q^{2}$ Statistics } \\
\hline \multirow[t]{2}{*}{$\mathrm{Q}^{2}(1)$} & 0.4202 & 0.0784 & 0.5734 & 0.4723 & 0.0707 \\
\hline & $(0.5170)$ & $(0.7800)$ & $(0.4490)$ & $(0.4920)$ & $(0.7900)$ \\
\hline \multirow[t]{2}{*}{$Q^{2}(10)$} & 9.1241 & 13.4850 & 13.1270 & 14.2380 & 12.0880 \\
\hline & $(0.5200)$ & $(0.1980)$ & $(0.2170)$ & $(0.1620)$ & $(0.2790)$ \\
\hline \multirow[t]{2}{*}{$Q^{2}(15)$} & 13.3340 & 22.8490 & 18.5500 & 21.2110 & 21.3040 \\
\hline & $(0.5770)$ & $(0.0870)$ & $(0.2350)$ & $(0.1300)$ & $(0.1270)$ \\
\hline \multirow[t]{2}{*}{$Q^{2}(20)$} & 13.9790 & 24.1650 & 21.2850 & 23.8860 & 23.0090 \\
\hline & $(0.8320)$ & $(0.2350)$ & $(0.3810)$ & $(0.2470)$ & $(0.2880)$ \\
\hline \multirow[t]{2}{*}{ ARCH-LM (1) } & 0.4148 & 0.0773 & 0.5663 & 0.4664 & 0.0698 \\
\hline & $(0.5199)$ & $(0.7811)$ & $(0.4521)$ & $(0.4950)$ & (0.7918) \\
\hline \multirow[t]{2}{*}{ ARCH-LM (5) } & 0.6571 & 0.4569 & 0.3577 & 0.4492 & 0.4664 \\
\hline & $(0.6562)$ & $(0.8083)$ & $(0.8772)$ & $(0.8138)$ & $(0.8013)$ \\
\hline \multirow[t]{2}{*}{ ARCH-LM (10) } & 0.8639 & 1.2779 & 1.3178 & 1.4003 & 1.1414 \\
\hline & $(0.5673)$ & $(0.2407)$ & $(0.2184)$ & $(0.1776)$ & (0.3297) \\
\hline \multirow[t]{2}{*}{ ARCH-LM (15) } & 0.8318 & 1.5124 & 1.2624 & 1.4060 & 1.3853 \\
\hline & $(0.6420)$ & $(0.0974)$ & $(0.2231)$ & $(0.1408)$ & $(0.1508)$ \\
\hline \multirow[t]{2}{*}{ ARCH-LM (20) } & 0.6535 & 1.2205 & 1.0919 & 1.1838 & 1.1266 \\
\hline & $(0.8708)$ & $(0.2333)$ & $(0.3552)$ & $(0.2646)$ & $(0.3191)$ \\
\hline \multirow[t]{2}{*}{ Jarque-Berra } & 1149.6990 & 1128.2690 & 954.7517 & 978.1423 & 1234.5780 \\
\hline & $(0.0000)^{*}$ & $(0.0000)^{*}$ & $(0.0000)^{*}$ & $(0.0000)^{*}$ & $(0.0000)^{*}$ \\
\hline
\end{tabular}

Note: $\mathrm{p}$ values are in parentheses

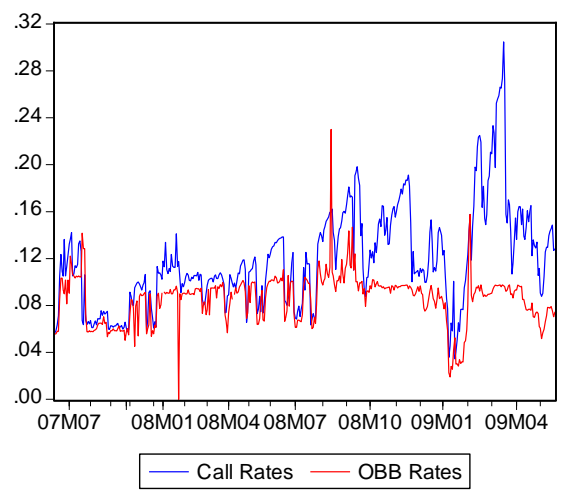

Figure 1. Trend in the call rates and open buy back ( OBB) rates from June 11, 2007 to May 20, 2009 


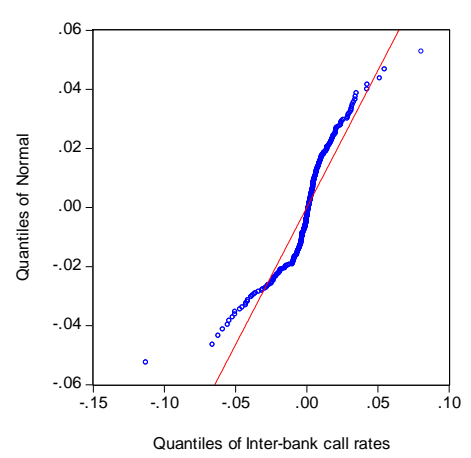

Figure 2. Quantile-Quantile Plot of Interbank call rate return series Based on the Full Sample (January 2, 2002 March 13, 2009)

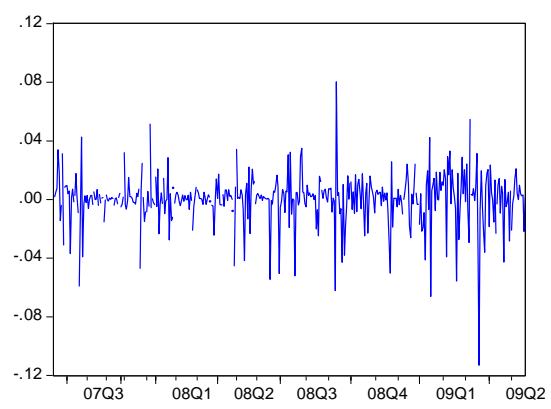

Figure 3. First-difference of daily inter bank call rates, June 11, 2007 - May 20, 2009

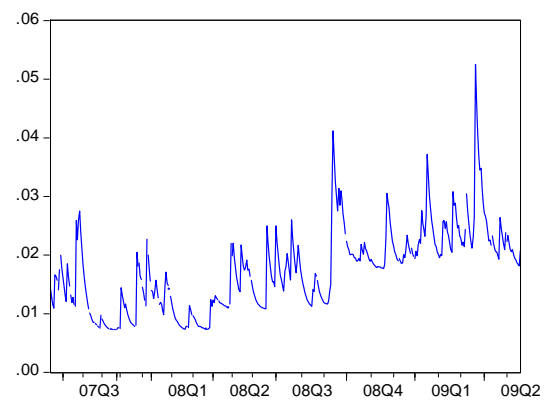

Figure 4. GARCH $(1,1)$ Conditional Standard Deviation For the Interbank call rate return series

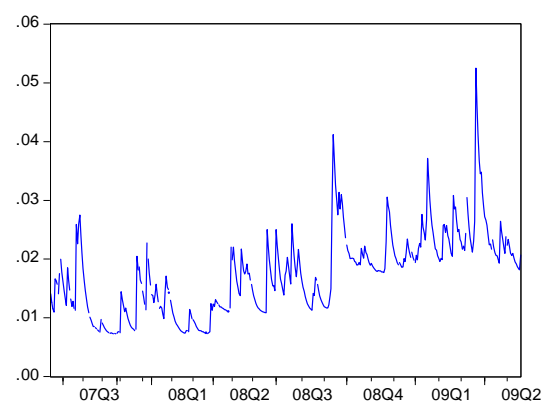

Figure 5. Augmented GARCH $(1,1)$ Conditional Standard Deviation For the Interbank call rate return series 


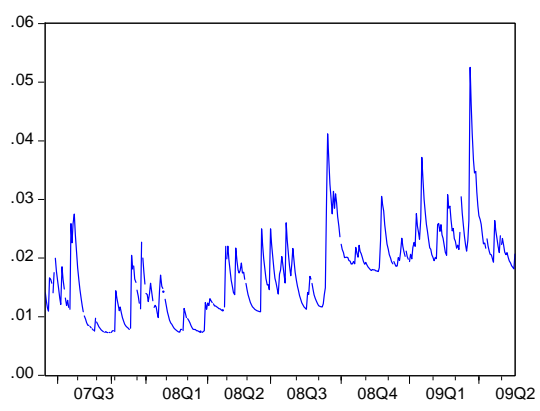

Figure 6. Augmented EGARCH $(1,1)$ Conditional Standard Deviation For the Interbank call rate return series

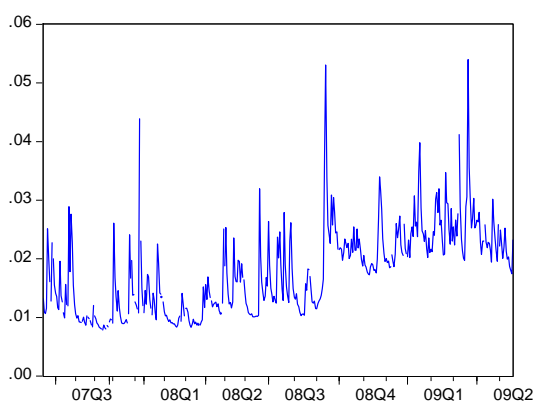

Figure 7. Augmented EGARCH $(1,1)$ Conditional Standard Deviation For the Interbank call rate return series

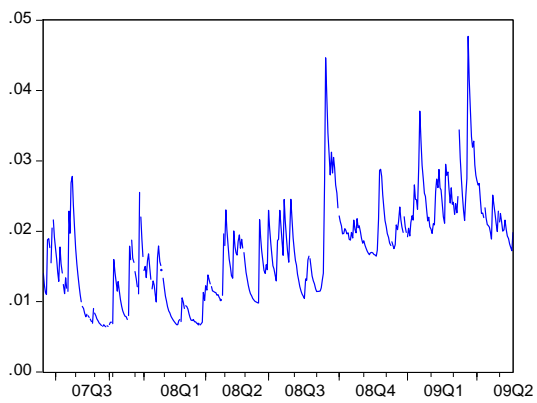

Figure 8. Augmented TS-GARCH $(1,1)$ Conditional Standard Deviation For the Interbank call rate return series

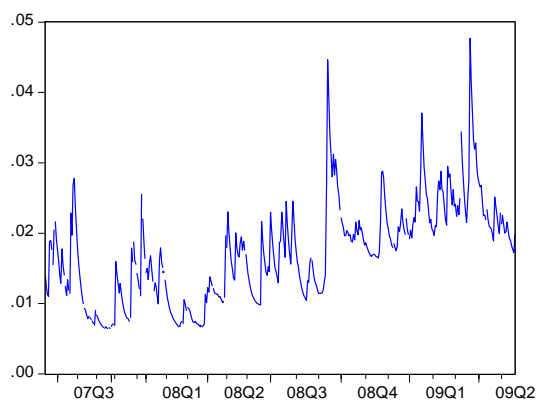

Figure 9. Augmented PARCH $(1,1)$ Conditional Standard Deviation For the Interbank call rate return series 